\title{
Pontas de pulverização e horários de aplicação no controle químico de ferrugem asiática da soja
}

\section{Spray nozzles and time of fungicide application on Asian soybean rust control}

\author{
Jackeline Matos do Nascimento ${ }^{1}$; Walber Luiz Gavassoni ${ }^{*}$; \\ Cristiano Marcio Alves de Souza²; Lilian Maria Arruda Bacchi²; \\ Ademar Pereira Serra ${ }^{3}$; Márcio Leizer Zaccaron ${ }^{4}$
}

\begin{abstract}
Resumo
O trabalho foi desenvolvido em Dourados-MS, com o objetivo de estudar o efeito de pontas de pulverização e horários de aplicação de fungicida no controle químico da ferrugem asiática da soja (Phakopsora pachyrhizi Sidow). Avaliaram-se quatro pontas de pulverização: jato plano defletor, jato plano defletor duplo, jato plano de faixa ampliada, jato plano duplo. As aplicações ocorreram nos horários de $14 \mathrm{~h}$ e $17 \mathrm{~h}$ 30min com pulverizador costal à pressão constante. $\mathrm{O}$ fungicida utilizado foi uma formulação comercial de epoxiconazol e piraclostrobina $\left(0,5 \mathrm{~L} \mathrm{ha}^{-1}\right)$. Foram coletados folíolos nos terços superior, médio e inferior para avaliação do número de lesões, urédias, e área foliar lesionada. Menor número de urédias no terço inferior foi observado em plantas que receberam aplicação de fungicida às $14 \mathrm{~h}$ via ponta jato plano defletor duplo em relação às demais pontas. A aplicação de fungicida, independente do tipo de ponta, não resultou em alterações nos níveis de controle da ferrugem asiática nos terços superior e médio. Menor desfolha e maior massa de mil grãos foram detectadas quando a aplicação foi realizada com a ponta jato plano defletor duplo em relação à jato plano defletor. A produtividade não foi afetada pelo uso de diferentes pontas e horários de aplicação do fungicida.

Palavras-chave: Glycine max, Phakopsora pachyrhizi, controle de doença, tecnologia de aplicação
\end{abstract}

\begin{abstract}
Spray nozzles were evaluated at two different spraying times (14h and $17 \mathrm{~h} 30 \mathrm{~m}$ ), in Mato Grosso do Sul, Brazil regarding Asian soybean rust control (Phakopsora pachyrhizi Sidow). Four spray nozzles were evaluated: deflector plain tips, double deflector plain tips, extended range flat spray tips and double plain tips. A commercial formulation of epoxiconazole and pyraclostrobin $\left(0,5 \mathrm{~L} \mathrm{ha}^{-1}\right)$ was sprayed in the plots. Soybean leaves were collected at the top, middle and lower canopy, for assessment of the number of lesions and uredinias. In addition, leaf area affected by P. pachyrhizi was estimated. Plots sprayed with double deflector plain tips had lower uredinia counts in the lower canopy compared to the other tips tested. Sprays done early in the afternoon with double deflector plain nozzles had lower uredinia counts compared to the other treatments. Smaller defoliation and greater a-thousand grain mass were detected in plots sprayed with fungicide using a double deflector plain tip compared to the deflector plain nozzle. Soybean yield was not affected by nozzles and time of fungicide spray.

Key words: Glycine max, Phakopsora pachyrhizi, disease control, spraying technology
\end{abstract}

\footnotetext{
${ }^{1}$ Eng $^{\mathrm{a}}$ Agr ${ }^{\mathrm{a}}$, Dr ${ }^{\mathrm{a}}$ em Produção Vegetal, Universidade Federal da Grande Dourados, UFGD, Dourados, MS. E-mail: jackeline_ms@ yahoo.com.br

${ }^{2}$ Profs. da Faculdade de Ciências Agrárias, UFGD, Dourados, MS. E-mail: walbergavassoni@ufgd.edu.br; cristianosouza@ufgd. edu.br; lilianbacchi@ufgd.edu.br

${ }^{3}$ Analista A, Empresa Brasileira de Pesquisa Agropecuária, EMBRAPA-CNPGC, Campo Grande, MS. E-mail: ademar.serra@ embrapa.br

${ }^{4}$ Eng $^{\mathrm{O}}$ Agr ${ }^{\circ}$, M.e University of Arkansas, Fayeteville, AK/EUA. E-mail: mlzaccar@email.uark.edu

* Autor para correspondência
} 


\section{Introdução}

A ferrugem asiática da soja é o principal problema fitossanitário da soja no Brasil. O dano ocasionado pela ferrugem asiática é a desfolha precoce, que pode impedir a completa formação dos grãos, e consequentemente implica na redução da produtividade (ROCHA et al., 2009). O montante de impacto da doença na produção depende do estádio da cultura, das condições climáticas favoráveis ao seu progresso após a constatação dos sintomas iniciais e do ciclo da cultivar utilizada (YANG et al., 1991). A doença é favorecida por chuvas bem distribuídas e longos períodos de molhamento. A temperatura ótima para o seu desenvolvimento varia entre $18^{\circ}$ e $26,5^{\circ} \mathrm{C}$ (EMBRAPA, 2010).

O controle de doenças em plantas deve integrar métodos culturais, genéticos e químicos (KLINGELFUSS; YORINORI, 2001). Produtos recomendados para o controle de ferrugem asiática têm como ingrediente ativo fungicidas do grupo dos triazois e estrobilurinas. Godoy e Canteri (2004) observaram que os fungicidas testados, pertencentes a esses grupos, em misturas, são eficientes no controle de P. pachyrhizi.

No controle da ferrugem asiática, é imprescindível que o fungicida atinja o alvo, isto é, o jato de pulverização deve ter características que permitam que as gotas atinjam o terço inferior das plantas. A utilização de pontas de pulverização de boa qualidade, que proporcionem cobertura homogênea com espectro de gotas uniforme, é importante para se obter uma eficiente aplicação de defensivo agrícola. Assim, o estudo do espectro de gotas produzidas pelas pontas de pulverização assume grande importância na eficiência de aplicação de produtos fitossanitários (CUNHA; TEIXEIRA, 2001).

A tecnologia de aplicação, como momento de aplicação e o tipo de ponta utilizada nas pulverizações influenciam o controle químico (SILVA et al., 2005). Trata-se da aplicação dos conhecimentos científicos a um determinado processo produtivo e que proporcionam a correta colocação de um produto biologicamente ativo no alvo, em quantidade necessária, de forma econômica e com mínimo de contaminação do ambiente. A aplicação adequada é aquela que, realizada no momento correto, horário adequado, que proporcione cobertura suficiente do alvo e nele deposita a quantidade de defensivo necessária para eliminar ou abrandar, com segurança, um determinado problema (MATUO, 1990).

A realização dessa pesquisa teve como objetivo avaliar o controle da ferrugem asiática da soja e a deposição da calda fungicida para as pontas jato plano de uso ampliado, jato plano duplo, jato plano defletor e jato plano defletor duplo, em dois horários de aplicação.

\section{Material e Métodos}

O trabalho foi desenvolvido na Fazenda Experimental da Universidade Federal da Grande Dourados (Latitude $22^{\circ} 14^{\prime} \mathrm{S}$, Longitude 54049'W e $452 \mathrm{~m}$ de altitude), localizada no município de Dourados-MS. O clima da região de Dourados é do tipo Cwa (clima mesotérmico úmido, verões quentes e invernos secos), com temperatura média do mês mais frio a $18,2^{\circ} \mathrm{C}$ e a do mês mais quente superior a $25^{\circ} \mathrm{C}$ (FIETZ; FISCH, 2009).

A semeadura foi realizada em 03/11/2006 com densidade de 12 plantas por metro linear e espaçamento entre fileiras de $0,45 \mathrm{~m}$. A cultivar de soja BRS 245 RR, crescimento determinado, com altura média de $77 \mathrm{~cm}$ (EMBRAPA, 2012), foi utilizada no experimento. A adubação foi efetuada durante a semeadura na linha do plantio, com $300 \mathrm{~kg} \mathrm{ha}^{-1}$ da fórmula 4-20-20. O controle de pragas e plantas daninhas foi realizado de acordo com as recomendações técnicas.

As aplicações foram realizadas em dois horários, às $14 \mathrm{~h}$ e às $17 \mathrm{~h} 30 \mathrm{~min}$. Utilizou-se equipamento de pulverização costal, à pressão constante $\left(\mathrm{CO}_{2}\right)$, dotado de uma barra porta-bicos de $2 \mathrm{~m}$, altura da barra de $0,5 \mathrm{~m}$ em relação à cultura, à velocidade de $3,7 \pm 0,1 \mathrm{~km} \mathrm{~h}^{-1}$. 
Foram avaliadas quatro diferentes pontas de pulverização, sendo jato plano de faixa ampliada (XR-11002), jato plano duplo (TJ60-11002), jato plano defletor (TT-11002) e jato plano defletor duplo (TTJ60-11002), em todas as aplicações, para os quatro tipos de pontas testadas, a pressão de trabalho foi de 3,5 bar. Nesta pressão, todas as pontas apresentam a mesma vazão $\left(0,85 \mathrm{~L} \mathrm{~min}^{-1}\right)$, de acordo com o fabricante (TEEJET, 2012a). A vazão das pontas foi quantificada em $0,83 \pm 0,16 \mathrm{~L} \mathrm{~min}^{-1}$.
O fungicida utilizado teve como ingrediente ativo epoxiconazol (133 $\left.\mathrm{g} \mathrm{L}^{-1}\right)$ e piraclostrobina ( $\left.50 \mathrm{~g} \mathrm{~L}^{-1}\right)$, na dose de $0,5 \mathrm{~L} \mathrm{ha}^{-1}$ do produto comercial com volume de aplicação $200 \mathrm{~L} \mathrm{ha}^{-1}$. No momento das aplicações para o controle da ferrugem asiática da soja foram determinadas a temperatura e a umidade relativa do ar, obtidos por meio de um termohigrometro (Tabela 1). Foram realizadas três aplicações de fungicidas, sendo a primeira de caráter preventivo, conforme Tabela 1 .

Tabela 1. Data, estádio fenológico e dados meteorológicos observados durante as aplicações de fungicidas em soja BRS 245 RR, com diferentes pontas de pulverização.

\begin{tabular}{ccccc}
\hline $\begin{array}{c}\text { Aplicação/ Estádio } \\
\text { Fenológico }^{*}\end{array}$ & Horário & $\begin{array}{c}\text { Velocidade do vento }(\mathrm{m} \\
\left.\mathrm{s}^{-1}\right)\end{array}$ & $\begin{array}{c}\text { Temperatura } \\
\left({ }^{\circ} \mathrm{C}\right)\end{array}$ & Umidade relativa (\%) \\
\hline \multirow{2}{*}{$07 / 01-\mathrm{R} 1$} & $14 \mathrm{~h} 00 \mathrm{~min}$ & 1,6 & 30,0 & 60 \\
& $17 \mathrm{~h} 30 \mathrm{~min}$ & 0,4 & 28,5 & 96 \\
\hline \multirow{2}{*}{$01 / 02-\mathrm{R} 5.1$} & $14 \mathrm{~h} 00 \mathrm{~min}$ & 0,9 & 31,4 & 88 \\
& $17 \mathrm{~h} 30 \mathrm{~min}$ & 1,3 & 28,2 & 92 \\
\hline \multirow{2}{*}{$24 / 02-\mathrm{R} 5.5$} & $14 \mathrm{~h} 00 \mathrm{~min}$ & 1,4 & 41,0 & 32 \\
& $17 \mathrm{~h} 30 \mathrm{~min}$ & 1,3 & 27,1 & 97 \\
\hline
\end{tabular}

*Yorinori (1996).

Fonte: Elaboração dos autores.

Antes de cada aplicação três papeis sensíveis a água e óleo (Syngenta ${ }^{\circledR}$, dimensões 76 x $26 \mathrm{~mm}$ ) foram fixados com auxílio de grampeador nos terços superior, médio e inferior de uma planta de soja no centro de cada parcela. Na terceira aplicação, no estádio R5.5 os papeis foram fixados apenas nos terços superior e médio, pois já não havia folhas no terço inferior das plantas.

Após as aplicações, os papeis foram armazenados em caixa com sílica-gel, para evitar que a umidade do ambiente interferisse nos resultados. Estes foram digitalizados com resolução de 300 dpi, e posteriormente avaliados com auxílio do programa computacional Conta-gotas versão 1.0, ano 2001(CANTERI et al., 2001). A densidade de gotas (número de gotas $\mathrm{cm}^{-2}$ ), diâmetro da mediana volumétrica (DMV) e porcentagem de cobertura (\%) foram determinados. Balan, Saab e Canteri (2005) avaliaram o software Conta-gotas e concluíram que este tem desempenho satisfatório e adequado para avaliação de gotas.

O experimento foi conduzido com delineamento de blocos ao acaso, com quatro repetições, em esquema de parcelas sub-subdivididas, sendo os horários as parcelas, as subparcelas as pontas de pulverização e as sub-subparcelas a posição (terços) dos papeis hidrosensíveis nas plantas.

Até a detecção da ferrugem asiática da soja na área experimental, o monitoramento foi realizado semanalmente por meio de coletas de 250 folíolos do terço inferior da cultura, na bordadura dos experimentos. A partir da detecção da doença, foram realizadas duas coletas com 30 folíolos removidos dos terços superior, médio e inferior das plantas de cada unidade experimental, para avaliação da ferrugem asiática da soja.

Avaliou-se o número de lesões e urédias por 
folíolo, área foliar lesionada (\%), utilizando-se a escala proposta por Canteri e Godoy (2003). A desfolha, por parcela, foi avaliada no momento em que uma área próxima ao experimento, onde não foi realizado o controle da ferrugem, atingiu $80 \%$ de desfolha (SARAIVA; LEITE; CASTRO, 2006).

A colheita dos grãos de soja foi realizada pela remoção manual de todas as plantas presentes em uma área de 5,4 $\mathrm{m}^{2}$, e em seguida procedeuse a trilha, com uma trilhadora estacionária. Os grãos foram acondicionados em sacos de papel, identificados e armazenados para limpeza manual e determinação de sua umidade. As amostras foram pesadas em balança de precisão, e calculada a produtividade da cultura, convertida para $13 \%$ de umidade (SARAIVA; LEITE; CASTRO, 2006) e expressos em $\mathrm{kg} \mathrm{ha}^{-1}$. A massa de mil grãos foi obtida a partir da média de três amostragens aleatórias dos grãos de cada parcela.

As análises foram efetuadas utilizando-se o software SAEG, versão 9.1, e os dados foram submetidos à análise de variância e as médias comparadas pelo teste Tukey, a 10\% de probabilidade de erro.

\section{Resultados e Discussão}

No Mato Grosso do Sul, na safra 2006/2007, a ferrugem asiática da soja foi relatada primeiramente em Laguna Caarapã, no dia 16/11/2006 em lavoura comercial em estádio R1 (CARVALHO et al., 2007). Contudo, na área experimental a doença foi detectada somente em 15/01/2007, 69 dias após a emergência, estádio fenológico R2. Não houve diferença estatística para a primeira avaliação da doença. Na segunda avaliação, aos 13 dias após a segunda aplicação, verificou-se diferença significativa no número de urédias de $P$. pachyrhizi no terço inferior das plantas de soja (Tabela 2). A aplicação realizada via ponta jato plano defletor duplo apresentou melhor controle da doença, diferindo-se estatisticamente da ponta jato plano de faixa ampliada.

Tabela 2. Lesões, urédias e área foliar lesionada por P. pachyrhizi, em folíolos do terço inferior e médio da soja BRS 245 RR (99 dias após a emergência, estádio fenológico R5.3) influenciadas pela aplicação de fungicida com diferentes pontas de pulverização.

\begin{tabular}{cllllllllllll}
\hline & \multicolumn{3}{c}{ Lesões } & \multicolumn{3}{c}{ Urédias } & \multicolumn{3}{c}{ Área Foliar Lesionada (\%) } \\
\hline Ponta & Inferior & \multicolumn{2}{c}{ Médio } & \multicolumn{2}{c}{ Inferior } & \multicolumn{2}{c}{ Médio } & \multicolumn{2}{c}{ Inferior } & Médio \\
\hline TTJ & 11,45 & a & 3,50 & a & 13,10 & b & 4,82 & a & 0,66 & a & 0,05 & a \\
XR & 25,20 & a & 6,48 & a & 36,86 & a & 9,08 & a & 1,13 & a & 0,12 & a \\
TT & 30,24 & a & 6,20 & a & 29,89 & ab & 8,74 & a & 2,46 & a & 0,17 & a \\
TJ & 18,58 & a & 2,69 & a & 24,01 & ab & 4,60 & a & 0,81 & a & 0,03 & a \\
\hline CV (\%) & 29,4 & & 57,8 & & 28,2 & & 47,3 & & 28,4 & & 9,8 \\
\hline
\end{tabular}

Médias seguidas por letras iguais nas colunas, não diferem entre si, pelo teste Tukey, a 10\% de probabilidade. Pontas: Jato plano defletor duplo (TTJ), Jato plano de faixa ampliada (XR), Jato plano defletor (TT) e Jato plano duplo (TJ). Para análise estatística os dados de lesões e urédias foram transformados em $\log (\mathrm{x})$ e de área foliar lesionada em arco seno $\sqrt{\mathrm{x}}+1$.

Fonte: Elaboração dos autores.

Madalosso (2007) trabalhou com pontas de pulverização no controle da ferrugem asiática da soja e não observou diferença no controle quando as pontas jato plano de faixa ampliada (XR 11002) e jato plano duplo (TJ60 11002) foram usadas nos estádios V9 e R1. As pontas de jato duplo leque (TJ60 11002) e cone (TXA 8002) foram as que apresentaram maior eficiência na redução da severidade da ferrugem. 
Houve interação entre pontas de pulverização e horário de aplicação na avaliação realizada aos 99 dias após a emergência, quando a cultura encontrava-se no estádio R5.3. Folíolos do terço inferior da cultura apresentaram menor número de lesões quando a aplicação foi realizada com a ponta jato plano defletor duplo, durante o primeiro horário de aplicação em relação às demais pontas (Tabela 3).

Tabela 3. Lesões causadas por P. pachyrhizi em folíolos de soja BRS 245 RR no terço inferior da cultura, em função das pontas de pulverização e horários de aplicação de fungicida, observadas na segunda avaliação ( 99 dias após a emergência, estádio fenológico R5.3), em Dourados-MS.

\begin{tabular}{ccccc}
\hline \multirow{2}{*}{ Horário de Aplicação } & \multicolumn{4}{c}{ Ponta de pulverização de jato de plano } \\
\cline { 2 - 5 } & TTJ & XR & TT & TJ \\
\hline $14 h 00$ min & $0,67 \mathrm{Bb}$ & $1,37 \mathrm{Aa}$ & $1,26 \mathrm{Aa}$ & $1,31 \mathrm{Aa}$ \\
$17 \mathrm{~h} 30 \mathrm{~min}$ & $1,14 \mathrm{Aa}$ & $1,16 \mathrm{Aa}$ & $1,17 \mathrm{Aa}$ & $0,89 \mathrm{Ab}$ \\
\hline
\end{tabular}

Médias seguidas por letras iguais, maiúsculas nas linhas e minúsculas nas colunas, não diferem entre si, pelo teste Tukey, a 10\% de probabilidade. Pontas: Jato plano defletor duplo (TTJ), Jato plano de faixa ampliada (XR), Jato plano defletor (TT) e Jato plano duplo (TJ). Para análise estatística os dados foram transformados em $\log (\mathrm{x})$.

Fonte: Elaboração dos autores.

O fungicida quando aplicado via ponta jato plano duplo proporcionou melhor controle da doença no horário das $17 \mathrm{~h} 30 \mathrm{~min}$. Apesar do tamanho de gotas produzidas pelas pontas jato plano de faixa ampliada e jato plano duplo serem as melhores alternativas para as pulverizações de fungicidas, pontas que produzem gotas maiores (jato plano defletor duplo) são mais adequadas em condições que favoreçam perdas, a temperaturas acima de $30^{\circ} \mathrm{C}$ (nas aplicações ocorridas às $14 \mathrm{~h}$ ) e umidade relativa abaixo de 55\% (BONINI, 2003).

$\mathrm{O}$ diâmetro da mediana volumétrica (DMV) representa o diâmetro da gota tal que metade do volume pulverizado é constituída de gotas de maior diâmetro e a outra metade, gotas de menor diâmetro (SANTOS, 2005). Comparando-se as pontas de pulverização (Tabela 4), observa-se que na primeira aplicação, não houve diferenças significativas para DMV. Na fase inicial do ciclo, a proteção da planta é mais fácil porque há uma maior deposição e a penetração do fungicida no dossel da cultura, pela menor quantidade de folhas (LOBO JUNIOR,
2006). Bettini, Gardanha Junior e Ramos (2005) trabalhando com aplicações via ponta XR $11002 \mathrm{sob}$ diferentes pressões, observaram que em plantas de algodão com índice de área foliar entre 1,46 e 10,30, gotas com diâmetro acima de $323 \mu \mathrm{m}$ depositaramse no terço superior, enquanto gotas entre 95 e 174 $\mu \mathrm{m}$ proporcionaram melhor distribuição no perfil da planta. Com estes valores de índice de área foliar relataram que não ocorreu deposição no terço inferior do algodoeiro.

Na segunda aplicação, a ponta jato plano duplo apresentou menor DMV e proporcionou os maiores valores de número de gotas $\mathrm{cm}^{-2}$ em relação à ponta jato plano defletor. Não houve diferenças entre pontas em relação à porcentagem de cobertura (Tabela 4). O diâmetro das gotas produzidas nesta pressão varia de acordo com o tipo de ponta. As pontas jato plano defletor e jato plano defletor duplo, produzem gotas classificadas como médias (175$200 \mu \mathrm{m})$, as pontas jato plano de faixa ampliada $(100-175 \mu \mathrm{m})$ produzem gotas finas e as de jato plano duplo gotas muito finas com DMV inferior a $100 \mu \mathrm{m}$ (TEEJET, 2012b). 
Tabela 4. Diâmetro da mediana volumétrica (DMV), densidade de gotas e cobertura em função da ponta de pulverização de fungicida em soja BRS 245 RR.

\begin{tabular}{|c|c|c|c|}
\hline \multirow{2}{*}{ Pontas de pulverização } & \multicolumn{3}{|c|}{$\mathrm{DMV}(\mu \mathrm{m})$} \\
\hline & 61 dias $-\mathrm{R} 1$ & 86 dias - R5.1 & 109 dias $-\mathrm{R} 5.5$ \\
\hline TTJ & $200,91 \mathrm{a}$ & $199,08 \mathrm{a}$ & $194,31 \mathrm{ab}$ \\
\hline $\mathrm{XR}$ & $192,04 \mathrm{a}$ & 199,08 a & $194,56 \mathrm{ab}$ \\
\hline TT & $208,33 \mathrm{a}$ & $212,46 \mathrm{a}$ & 209,62 a \\
\hline $\mathrm{TJ}$ & $202,25 \mathrm{a}$ & $170,31 \mathrm{~b}$ & $169,94 \mathrm{~b}$ \\
\hline $\mathrm{CV}(\%)$ & 27,1 & 19,3 & 18,7 \\
\hline \multicolumn{4}{|c|}{ Densidade de gotas (Número de gotas $\mathrm{cm}^{-2}$ ) } \\
\hline TTJ & $198,92 \mathrm{ab}$ & 304,38 a & $428,69 \mathrm{~b}$ \\
\hline $\mathrm{XR}$ & $194,07 \mathrm{ab}$ & $222,38 \mathrm{~b}$ & $471,39 \mathrm{ab}$ \\
\hline TT & $164,58 \mathrm{~b}$ & $201,42 b$ & $395,69 \mathrm{~b}$ \\
\hline $\mathrm{TJ}$ & $261,37 \mathrm{a}$ & $295,99 \mathrm{a}$ & $561,88 \mathrm{a}$ \\
\hline $\mathrm{CV}(\%)$ & 56,5 & 37,3 & 31,6 \\
\hline \multicolumn{4}{|c|}{ Cobertura $(\%)$} \\
\hline TTJ & $13,96 \mathrm{a}$ & $21,64 \mathrm{a}$ & $27,37 \mathrm{a}$ \\
\hline $\mathrm{XR}$ & $13,76 \mathrm{a}$ & $16,46 \mathrm{a}$ & $27,81 \mathrm{a}$ \\
\hline $\mathrm{TT}$ & $11,12 \mathrm{a}$ & 16,83 a & $28,44 \mathrm{a}$ \\
\hline $\mathrm{TJ}$ & $18,50 \mathrm{a}$ & $16,58 \mathrm{a}$ & $30,94 \mathrm{a}$ \\
\hline CV (\%) & 68,4 & 45,9 & 45,9 \\
\hline
\end{tabular}

Médias seguidas por letras iguais na coluna, não diferem entre si, pelo teste Tukey, a 10\% de probabilidade. Pontas: Jato plano defletor duplo (TTJ), Jato plano de faixa ampliada (XR), Jato plano defletor (TT) e Jato plano duplo (TJ).

Fonte: Elaboração dos autores.

Houve diminuição dos valores de DMV, densidade de gotas e cobertura da área, na segunda aplicação, estádio R5.1, conforme aproximouse da base da planta (Tabela 5). As gotas médias depositaram-se no terço superior, enquanto as gotas finas depositaram-se nos terços médio e inferior. Na terceira aplicação (soja em R5.5), não houve diferença em relação a estes parâmetros. Estes resultados estão em concordância com Santos (2005), que ressalta que as gotas finas e leves depositam-se melhor e mais facilmente nos alvos de deposição estreitas, penetram melhor no dossel da cultura, e gotas grossas ou mais pesadas depositamse melhor em áreas mais largas (posicionadas mais horizontalmente), tendo facilidade de deposição na parte externa das plantas e grande dificuldade de penetração dentro das culturas.

A interação entre ponta de pulverização e horário de aplicação, em relação ao número de gotas $\mathrm{cm}^{-2}$, na primeira aplicação (estádio R1), estão apresentadas na Tabela 6 . No primeiro horário não houve diferença significativa entre as pontas quanto ao número de gotas $\mathrm{cm}^{-2}$, mas houve diferença entre as médias no segundo horário de aplicação (17h30min) indicando que, sob condições climáticas favoráveis (temperatura $28,5^{\circ} \mathrm{C}$ e umidade relativa do ar 96\%), a ponta jato plano duplo proporcionou melhor cobertura em relação às outras. 
Tabela 5. Diâmetro da mediana volumétrica (DMV), densidade de gotas e cobertura em função da posição na planta da soja BRS 245 RR.

\begin{tabular}{|c|c|c|c|}
\hline \multirow[t]{2}{*}{ Posição na planta } & \multicolumn{3}{|c|}{$\operatorname{DMV}(\mu \mathrm{m})$} \\
\hline & 61 dias $-\mathrm{R} 1$ & 86 dias - R5.1 & 109 dias - R5.5 \\
\hline Terço superior & $211,62 \mathrm{a}$ & $242,52 \mathrm{a}$ & $221,37 \mathrm{a}$ \\
\hline Terço médio & $192,34 \mathrm{a}$ & $183,33 \mathrm{~b}$ & $162,84 \mathrm{a}$ \\
\hline Terço inferior & $198,69 \mathrm{a}$ & $159,84 \mathrm{c}$ & - \\
\hline \multicolumn{4}{|c|}{ Densidade de gotas (Número de gotas $\mathrm{cm}^{-2}$ ) } \\
\hline Terço superior & $402,03 \mathrm{a}$ & $537,56 \mathrm{a}$ & $586,12 \mathrm{a}$ \\
\hline Terço médio & $157,59 \mathrm{~b}$ & $187,61 \mathrm{~b}$ & $342,69 \mathrm{a}$ \\
\hline Terço inferior & $54,58 \mathrm{c}$ & $42,94 \mathrm{c}$ & - \\
\hline \multicolumn{4}{|c|}{ Cobertura (\%) } \\
\hline Terço superior & 33,06 a & $43,30 \mathrm{a}$ & $42,50 \mathrm{a}$ \\
\hline Terço médio & $8,31 \mathrm{~b}$ & $8,97 \mathrm{~b}$ & $14,78 \mathrm{a}$ \\
\hline Terço inferior & $1,91 \mathrm{c}$ & $1,45 \mathrm{c}$ & - \\
\hline
\end{tabular}

Médias seguidas por letras iguais na coluna, não diferem entre si, pelo teste Tukey, a 10\% de probabilidade.

Fonte: Elaboração dos autores.

Tabela 6. Densidade de gotas (gotas $\mathrm{cm}^{-2}$ ) em função das pontas de pulverização e horário de aplicação de fungicida em soja BRS 245 RR, aos 61 dias após a semeadura, estádio R1.

\begin{tabular}{ccccccccc}
\hline \multirow{2}{*}{ Horário de Aplicação } & \multicolumn{9}{c}{ Ponta de Pulverização } \\
\cline { 2 - 8 } & \multicolumn{2}{c}{ TTJ } & \multicolumn{2}{c}{ XR } & \multicolumn{3}{c}{ TJ } \\
\hline 14h00min & 198,08 & A a & 231,89 & A a & 122,58 & A b & 194,00 & A b \\
17h30min & 199,75 & B a & 156,25 & B a & 206,58 & B a & 328,75 & A a \\
\hline CV (\%) & \multicolumn{7}{c}{56,5} \\
\hline
\end{tabular}

Médias seguidas por letras iguais não diferem entre si, maiúsculas na linha e minúsculas na coluna, pelo teste Tukey, a $10 \%$ de probabilidade. Pontas: Jato plano defletor duplo (TTJ), Jato plano de faixa ampliada (XR), Jato plano defletor (TT) e Jato plano duplo (TJ).

Fonte: Elaboração dos autores.

Para o fator horário de aplicação, as pontas jato plano duplo e jato plano defletor proporcionaram maior número de gotas $\mathrm{cm}^{-2}$ para a aplicação das 17 h30min em relação a aplicação feita às $14 \mathrm{~h}$. Nos dois horários, as condições ambientais estavam favoráveis a aplicação, porém, às 17h30min, a temperatura estava menor $\left(28,2^{\circ}\right)$ e umidade maior $(92 \%)$ quando comparadas às $14 \mathrm{~h}$. Com isso, ocorreram menores perdas por evaporação de gotas menores, aumentando a densidade de gotas. Segundo ANDEF (2004), o ideal para a aplicação seria umidade relativa acima de $55 \%$ e temperatura igual ou inferior a $30^{\circ} \mathrm{C}$, pois a temperatura e umidade exercem grande influência sobre a duração de vida da gota gerada pelo sistema de pulverização, comprometendo a aplicação.

Mendes e Cabeda (2005) estudaram, para as condições de Palotina-PR na safra 2004, a aplicação 
de fungicidas na cultura da soja visando o controle da ferrugem asiática. Os autores avaliaram o desempenho das pontas jato plano de uso ampliado e jato plano duplo, em condições desfavoráveis de temperatura e umidade relativa (13h) e em condições favoráveis (19h). Naquelas condições detectaram interação entre pontas e horários de aplicação. A ponta jato plano duplo apresentou melhor desempenho que a jato plano de uso ampliado no horário das $19 \mathrm{~h}$.

$\mathrm{Na}$ Tabela 7 estão apresentados os dados de densidade de gotas da aplicação aos 86 dias após a emergência. Observou-se interação significativa entre as pontas de pulverização e posição do papel nos terços da planta. Na posição superior a ponta jato plano duplo diferenciou-se das demais pontas com maior número de gotas $\mathrm{cm}^{-2}$. Na posição média, a aplicação realizada com a ponta jato plano defletor duplo resultou em maior número de gotas $\mathrm{cm}^{-2}$, diferenciando-se da ponta jato plano de uso ampliado e jato plano defletor. É esperado que, em geral, sob condições favoráveis, pontas que produzam gotas de menor tamanho promovam melhor cobertura do alvo (CUNHA; REIS; SANTOS, 2006).

Tabela 7. Densidade de gotas (gotas $\mathrm{cm}^{-2}$ ) em função dos tipos de pontas de pulverização e da posição na planta de soja BRS 245 RR, na $2^{a}$ aplicação (estádio R5.1).

\begin{tabular}{|c|c|c|c|c|c|c|c|c|}
\hline \multirow{3}{*}{$\begin{array}{c}\text { Posição na planta } \\
\text { Superior }\end{array}$} & \multicolumn{8}{|c|}{ Ponta de Pulverização } \\
\hline & \multicolumn{2}{|c|}{ TTJ } & \multicolumn{2}{|c|}{$\mathrm{XR}$} & \multicolumn{2}{|l|}{$\mathrm{TT}$} & \multicolumn{2}{|c|}{$\mathrm{TJ}$} \\
\hline & 564,88 & $\mathrm{BC} \mathrm{a}$ & 460,25 & $\mathrm{BC} \mathrm{a}$ & 447,62 & $\mathrm{C} \mathrm{a}$ & 677,50 & $\mathrm{~A} \mathrm{a}$ \\
\hline Médio & 275,75 & $\mathrm{Ab}$ & 152,50 & $\mathrm{~B} \mathrm{~b}$ & 135,38 & $\mathrm{~B} \mathrm{~b}$ & 186,83 & $\mathrm{AB} \mathrm{b}$ \\
\hline Inferior & 72,50 & $\mathrm{Ac}$ & 54,38 & $\mathrm{Ab}$ & 21,25 & $\mathrm{Ac}$ & 23,62 & $\mathrm{Ac}$ \\
\hline $\mathrm{CV}(\%)$ & 37,3 & & & & & & & \\
\hline
\end{tabular}

Médias seguidas por letras iguais, maiúsculas na linha e minúsculas na coluna, não diferem entre si, pelo teste Tukey, a 10\% de probabilidade. Pontas: Jato plano defletor duplo (TTJ), Jato plano de faixa ampliada (XR), Jato plano defletor (TT) e Jato plano duplo (TJ).

Fonte: Elaboração dos autores.

A ponta jato plano foi menos eficiente em proporcionar a penetração dos produtos no dossel em relação a ponta jato plano duplo que produz gotas finas. Viana et al. (2008) observaram que aplicações com a ponta jato plano duplo proporcionam cobertura de gotas homogênea nas três posições de amostragem, acompanhando a tendência de homogeneidade no tamanho de gotas, nos terços médio e inferior, a cobertura foi menor para pontas jato plano defletor, jato plano de faixa ampliada e cone. As pontas jato plano defletor, jato plano de faixa ampliada e cone resultam em maior cobertura na posição superior da planta, também influenciada por retenção de gotas maiores nesta posição e maior exposição do alvo no terço superior. Não houve diferença significativa entre pontas no terço inferior. No caso dos fungicidas, a desuniformidade na deposição nas partes mais baixas e internas do dossel resulta em baixa eficácia no controle das doenças.

A massa de mil grãos apresentou-se 3,3\% menor e a desfolha $15,1 \%$ maior em parcelas que receberam o fungicida via ponta jato plano defletor comparado a ponta jato plano defletor duplo (Tabela 8). Entretanto não foi verificado efeito dos tratamentos sobre a produtividade. É possível que a ocorrência tardia da doença e o baixo potencial de inóculo tenham contribuído para tal fato. Ingram et al. (1981) relatam que o efeito da desfolha sobre a peso de grãos é causado pela redução da interceptação da luz e da fotossíntese. A tolerância da soja á desfolha é dependente de vários fatores 
como o nível de desfolha, o estádio fenológico na época da desfolha e fatores ambientais (PEDIGO; HUTCHINS; HIGLEY, 1986; PARCIANELLO et al., 2004). Níveis de desfolha superiores a 50\% reduzem o número de vagens e de grãos por planta de soja quando efetuados nos estádios R3 e R5 (RIBEIRO; COSTA, 2000).

Não houve influência das diferentes pontas de pulverização na produção de grãos (Tabela 8).
Cunha, Reis e Santos (2006) também não obtiveram diferença significativa no rendimento dos grãos entre as parcelas tratadas com fungicidas por diferentes pontas de pulverização, atribuindo ao fato de que, mesmo sendo significativas as diferenças entre a deposição da calda fungicida proporcionada pelas diferentes pontas, elas foram insuficientes para afetar a produtividade das plantas.

Tabela 8. Massa de mil grãos, produtividade da cultura e porcentagem de desfolha de soja BRS 245 RR, com aplicações realizadas com diferentes pontas de pulverização.

\begin{tabular}{|c|c|c|c|c|}
\hline Ponta de pulverização & $\begin{array}{l}\text { Massa de mil grãos } \\
(\mathrm{g})\end{array}$ & $\begin{array}{l}\text { Produtividade } \\
\quad\left(\mathrm{kg} \mathrm{ha}^{-1}\right)\end{array}$ & $\begin{array}{r}\text { Desfo } \\
(\%)\end{array}$ & lha \\
\hline TTJ & $133,70 \quad \mathrm{a}$ & $3600,8 \quad a$ & 39,1 & $\mathrm{~b}$ \\
\hline $\mathrm{XR}$ & $132,08 \quad a b$ & $3707,9 \quad a$ & 39,9 & $a b$ \\
\hline $\mathrm{TT}$ & $129,23 \quad b$ & $3508,0 \quad a$ & 47,8 & $\mathrm{a}$ \\
\hline $\mathrm{TJ}$ & $130,66 \mathrm{ab}$ & $3439,3 \quad \mathrm{a}$ & 44,8 & $\mathrm{ab}$ \\
\hline CV (\%) & 2,3 & 7,2 & 42,9 & \\
\hline
\end{tabular}

Médias seguidas por letras iguais não diferem entre si, pelo teste Tukey, a 10\% de probabilidade. Pontas: Jato plano defletor duplo (TTJ), Jato plano de faixa ampliada (XR), Jato plano defletor (TT) e Jato plano duplo (TJ). Para análise estatística os dados de desfolha foram transformados em arco seno $\sqrt{ } \mathrm{X}+1$.

Fonte: Elaboração dos autores.

\section{Conclusão}

O fungicida epoxiconazol + piraclostrobina, na dose de $0,5 \mathrm{~L}$ ha, aplicado via ponta tipo jato plano defletor duplo proporciona maior controle da ferrugem asiática da soja, evidenciado pelo menor número de urédias no terço inferior, menor desfolha e maior massa de mil grãos. Aplicação via ponta jato plano duplo proporcionou gotas com menores DMV, e maior densidade de gotas em relação à ponta jato plano defletor. A produtividade não foi afetada pelo uso de diferentes pontas e horários de aplicação do fungicida.

\section{Agradecimentos}

À Capes, pela bolsa de estudo concedida à primeira autora. Ao CNPq, pela bolsa de produtividade em pesquisa concedido ao terceiro autor. À FUNDECT-MS, pelo apoio à pesquisa.

\section{Referências}

ASSOCIAÇÃO NACIONAL DE DEFESA VEGETAL ANDEF. Manual de tecnologia de aplicação de produtos fitossanitários. Campinas: Línea Creativa, 2004. 50 p.

BALAN, M. G.; SAAB, O. J. G. A.; CANTERI, M. G. Uso do software conta-gotas na avaliação da cobertura de pulverização em alvos artificiais. In: CONGRESSO BRASILEIRO DE AGROINFORMÁTICA, 5., 2005, Londrina. Resumos... Londrina: SBI-AGRO, 2005. Disponível em: $\quad<\mathrm{http}: / /$ www.sbiagro.org.br/pdf/v congresso/Trabalho119.pdf.>. Acesso em: 16 jul. 2012. 
BETTINI, P. C.; GARDANHA JUNIOR, C. D.; RAMOS, H. H. Eficácia da penetração de gotas de pulverização na copa do algodoeiro em diferentes alturas de plantas. In: CONGRESSO BRASILEIRO DE ALGODÃO, 5., 2005, Salvador. Anais eletrônicos... Salvador: CNPA, 2005. Disponível em: <http://www.cnpa.embrapa.br/produtos/ algodao/publicacoes/trabalhos_cba5/226.pdf.>. Acesso em: 15 jul. 2012.

BONINI, J. V. Tecnologia de aplicação de fungicidas na cultura da soja. 2003. Dissertação (Mestrado em Agronomia) - Universidade Federal de Santa Maria, Santa Maria.

CANTERI, M. G.; FÜRSTENBERGER, A. L. F.; GARCIA, L. C.; JUSTINO, A. Conta-gotas: sistema para análise de eficiência de pulverização. In: CONGRESSO PAULISTA DE FITOPATOLOGIA, 24., 2001, Piracicaba. Anais... Jaboticabal: Grupo Paulista de Fitopatologia, 2001. v. 27, p. 136-136.

CANTERI, M. G.; GODOY, C. V. Escala diagramática para avaliação da severidade da ferrugem da soja. In: CONGRESSO PAULISTA DE FITOPATOLOGIA, 26., 2003, Araras. Anais... Botucatu: Grupo Paulista de Fitopatologia, 2003. v. 29, p. 89-89.

CARVALHO, P. M.; OLIVEIRA, M.; PEZZONI, T.; ZACCARON, M. L.; TOMONAGA, K. T.; SAN MARTIN, M. N.; PONTIM, B. C. A.; BARROS, R.; URANO, E. O. M.; SBABO, L. A. X.; GAVASSONI, W.L. Ferrugem asiática da soja na região sul de Mato Grosso do Sul na safra 2006/2007. In: CONGRESSO BRASILEIRO DE FITOPATOLOGIA, 40., 2007, Maringá. Anais... Maringá: SBF, 2007. v. 32, p. S187.

CUNHA, J. P. A. R.; REIS, E. F. dos; SANTOS, R. O. Controle químico da ferrugem asiática da soja em função de pontas de pulverização e de volumes de calda. Ciência Rural, Santa Maria, v. 36, n. 5, p. 1360-1366, 2006.

CUNHA, J. P. A. R.; TEIXEIRA, M. M. Características técnicas de bicos de pulverização hidráulicos de jato plano. Revista Brasileira de Engenharia Agrícola e Ambiental, Campina Grande, v. 5, n. 2, p. 344-348, 2001.

EMPRESA BRASILEIRA DE PESQUISA AGROPECUÁRIA - EMBRAPA. BRS 245 RR. 2012 Disponível em: <http://www.cnpso.embrapa.br/ download/cultivares2006/brs245rr.pdf. $>$. Acesso em: 16 jul. 2012.

Tecnologias de produção de soja região central do Brasil 2011. Londrina: Embrapa, 2010. 255 p. (Embrapa Soja, n. 14). Disponível em: <http://www. cnpso.embrapa.br/download/Sistema_Producao14 VE.pdf.>. Acesso em: 16 jul. 2012.
FIETZ, C. R.; FISCH, G. F. Avaliação de modelos de estimativa do saldo de radiação e do método PriestleyTaylor para região de Dourados, MS. Revista Brasileira de Engenharia Agrícola e Ambiental, Campina Grande, v. 13, n. 4, p. 449-453, 2009.

GODOY, C. V.; CANTERI, M. G. Efeitos protetor, curativo e erradicante de fungicidas no controle da ferrugem da soja causada por Phakopsora pachyrhizi, em casa de vegetação. Fitopatologia Brasileira, Brasília, v. 29, n. 1, p. 97-101, 2004.

INGRAM, K. T.; HERZOG, D. C.; BOOTE, K. J.; JONES, J. W.; BARFIELD, C. S. Effects of defoliating pests on soybean canopy $\mathrm{CO}_{2}$ exchange and reproductive growth. Crop Science, Madison, v. 21, n. 6, p. 961-968, 1981.

KLINGELFUSS, L. H.; YORINORI, J. T. Infecção latente de Colletotrichum truncatum e Cercospora kikuchii em soja. Fitopatologia Brasileira, Brasília, v. 26, n. 2, p. 158-164, 2001.

LOBO JUNIOR, M. I. Combate com tecnologia de aplicação. A Granja, São Paulo, out. 2006. Disponível em: <http://pt.scribd.com/doc/23738123/Tecnologia-deAplicacao-de-Agroquimicos.>. Acesso em: 17 jul. 2012.

MADALOSSO, M. G. Espaçamento entre linhas e pontas de pulverização no controle de Phakopsora pachyrhizi Sidow. 2007. Dissertação (Mestrado em Agronomia) Universidade Federal de Santa Maria, Santa Maria.

MATUO, T. Técnicas de aplicação de defensivos agrícolas. Jaboticabal: FUNEP. 1990. 139 p.

MENDES, C. S.; CABEDA, R. Pontas para fungicidas foliares na cultura da soja. In: TECNOLOGIA DE APLICAÇÃO DE DEFENSIVOS AGRÍCOLAS, 3., 2005. Cascavel. Encontro... Cascavel: Grupo TA, 2005. p. 72-98.

PARCIANELlO, G.; COSTA, J. A.; PIRES, J. L. F.; RAMBO, L.; SAGGIN, K. Tolerância da soja ao desfolhamento afetada pela redução do espaçamento entre fileiras. Ciência Rural, Santa Maria, v. 34, n. 2, p. 357-364, 2004.

PEDIGO, L. P.; HUTCHINS, S. H.; HIGLEY, L. G. Economic injury levels in theory and practice. Annual Review of Entomology, Palo Alto, v. 31, p. 341-368, 1986.

RIBEIRO, A. L. P.; COSTA, E. C. Desfolhamento em estádios de desenvolvimento da soja, cultivar BR 16, no rendimento de grãos. Ciência Rural, Santa Maria, v. 30, n. 5 , p. $767-771,2000$. 
ROCHA, C. L.; GUERRA, D. S.; RODRIGUES M. A. T.; BEGLIOMINI, E. Eficiência do fungicida piraclostrobin + metconazole (BAS 55601F) no controle da ferrugem asiática da soja. In: REUNIÃO DE PESQUISA DE SOJA DA REGIÃO SUL, 37., 2009, Porto Alegre. Resumos... Porto Alegre: UFRGS, 2009. Disponível em: <http:// www6.ufrgs.br/agronomia/materiais/XXXVIIRPSSul. pdf.>. Acesso em: 19 jul. 2012.

SANTOS, J. M. F. dos. Mini curso: tecnologia de aplicação de pesticidas (terrestre e aérea) tecnologia de aplicação de defensivos agrícolas. São Paulo: Instituto Biológico, 2005.

SARAIVA, O. F.; LEITE, R. M. V. B. C.; CASTRO, C. de. Ata XXVIII Reunião de Pesquisa de soja da Região Central do Brasil, Embrapa Soja, Londrina, PR, 2006. p. 246.

SILVA, L. H. C. P.; CAMPOS, H. D.; SILVA, J. R. C.; RIBEIRO, G. C.; NEVES, D. L. Ferrugem asiática em Goiás: Controle químico e hospedeiros alternativos. In: WORKSHOP BRASILEIRO SOBRE A FERRUGEM ASIÁTICA, 1., 2005. Uberlândia. Anais... Uberlândia: EDUFU, 2005. cap. 14, p. 135-179.
TEEJET, catálogo 50, 20 p. 2012. Disponível em: $<$ http:// www.teejet.com/media/102542/173-192 cat50 port lr.pdf. $>$. Acesso em: 02 jul. 2012b. , catálogo 51,150 p. 2011. Disponível em: <http:// www.teejet.com/media/431274/cat51_portuguese.pdf.>. Acesso em: 02 jul. 2012a.

VIANA, R. G.; FERREIRA, R. L.; TEIXEIRA, M. M.; CECON, P. R.; SOUZA, V. R. de. Deposição de gotas no dossel da soja por diferentes pontas de pulverização hidráulica e pressões de trabalho. Engenharia na Agricultura, Viçosa, MG, v. 16, n. 4, p. 428-428, 2008.

YANG, X. B.; TSCHANZ, A. T.; DOWLER, W. M.; WANG, T. C. Development of yield loss models in relation to reductions of components of soybeans infected with Phakopsora pachyrhizi. Phytopathology, St. Paul, v. 81, n. 11, p. 1420-1426, 1991.

YORINORI, J. T. Cancro da haste da soja: epidemiologia e controle. Londrina: Embrapa-CNPSo, 1996. (Circular técnica, 14). 
